\title{
Increase in the efficiency of water transport of bulk mineral cargo by the segregation of feedstock at the initial technological stage
}

\author{
Yuriy Lyashenko ${ }^{1}$, Elena Menshenina ${ }^{2 *}$,Elena Revyakina $^{3}$ \\ ${ }^{1}$ Department of Transport Safety and Road Infrastructure Management, Shakhty Road Institute (branch) of Platov South-Russian \\ State Polytechnic University, no. 1, pl. Lenin, Shakhty Rostov region, 346500, Russia \\ ${ }^{2}$ Institute of Water Transport named after G. Ya. Sedov, branch of Admiral Ushakov Maritime State University, Sedov Street 8 , \\ Rostov-on-Don, 344006, Russia \\ ${ }^{3}$ Don State Technical University (DSTU), №1, pl. Gagarin, Rostov-on-Don, 344010, Russia
}

\begin{abstract}
The paper gives the analysis of the volume of transportation of bulk mineral cargoes by water transport. It is established that the problem of the use of technological processes for sorting non-metallic building materials and coals transported by water transport is relevant. It is revealed that in the applied beneficiation system of crushed stone it is possible to reduce energy consumption due to the segregation of material into commercial fractions at the crushing stage by combining operations. The developed design of the receiving - segregation hopper is considered which allows classifying the feedstock at the initial technological stage of the production of crushed sandstone. A patented design of a segregation hopper and a technological scheme with its use are described. The volume of material sent to the crushing process is reduced by up to $50 \%$ due to the separation of particles of commercial fractions, which helps to reduce the production cost of a unit of the finished product. The principle of operation of the hopper is based on the difference in the rolling speed of particles of various sizes. The influence of the geometrical parameters of the chute and the size of the initial material on the capacity of the hopper is investigated. The influence of the slope angle of the chute and the particle size on the production parameters of the installation is proved. The configuration at which the drain wall achieves the highest throughput is determined.
\end{abstract}

\section{Introduction}

The transportation of nonmetallic minerals, which serve as raw materials for the production of building materials, constitutes a significant share in national cargo transportation. The share of water transport in the structure of supplies of building materials to the facilities under construction reaches 5\%. This share tends to increase due to the low cost of transportation and constantly increasing volumes of construction. According to experts (Kommersant, 2017), the cost of railway transportation of construction materials is 50-80 kopecks per ton-kilometer, for transportation by road the same indicator is 5-6 rubles, with a speed gain of 2-3 times. The transportation of construction cargo by water transport with reloading to the shore is 40-60 kopecks per one ton-kilometer.

Often the sand and gravel mixture is mined in river beds. In this case, loading and unloading operations can be accompanied by crushing and screening operations, forming a technological process for the beneficiation of nonmetallic minerals [1]. As a result, a higher quality of building materials is provided and the carrying capacity of ships is used more fully.

Thus, for example, the production association "Nerudmaterialy" (PONM), located in Tatarstan, is a structural subdivision of JSC "SC "Tatflot" and has the largest capacities in the region for the processing of nonmetallic building materials (NBM). The advantage of the waterway of delivery is the transportation of feedstock directly from the mining enterprises developing the deposits of the Nizhnekamsk basin and the channel deposits of the Volga and Kama rivers. The extracted materials are sorted into fractions (coarse sand, gravel 520 and gravel 20), the upper fractions of gravel are processed into crushed stone. The unloading of barges with mineral raw materials is carried out by a floating crane to the berths. Then it is transferred to beneficiation to crushing and screening plants for separating sand and gravel (Tatflot, official website).

The most massive transported cargo is coal. The crushing process can be used when loading it onto a ship in order to prevent the ingress of pieces that do not meet the required grade. Such loading technologies, supplemented by the benefaction process, are widely used in the Far East basin, for example, in the port of Vostochny.

The technology for the production of crushed stone mined in river beds includes two main stages: the first stage is sorting of various fractions from sand to gravel of various sizes and the second one is the processing of coarse gravel into crushed stone [2]. The separation of bulk materials into products of various sizes is one of the

*Corresponding author:menshenina@iwtsedov.ru 
main beneficiation processes for the production of crushed stone.

Due to the implementation of the results of research and development aimed to improve the technology of sandstone beneficiation, in recent years, new energysaving technologies have been applied at the existing crushing and screening plants.

\section{Analysis of the applied means of mechanization for the production of crushed stone}

The source raw material for the production of crushed stone is usually sandstone with a tensile strength of up to $1000 \mathrm{~kg} / \mathrm{cm}^{2}$ and a lump size of $0 \div 100 \mathrm{~mm}$ up to $50 \%$ of the total volume. The excavation of the mass is carried out by dredgers of the type Praga, PZS, PChS, LS, as well as by floating caravans, which send the mass to the receiving hopper of the crushed stone plant for processing.

The technological process of the beneficiation of crushed stone can be conditionally divided into three stages:

- The first stage is the draining of the extracted mass;

- The second stage is the sorting the mass into size classes;

- The third stage is the stage of crushing the fraction larger than $40 \mathrm{~mm}$.

After being developed by hydraulic monitors, the mineral construction mass is delivered by barges and unloaded by floating cranes to the berths. At the second stage, the rock mass is fed to the screen by means of a belt conveyor, with the help of which it is divided into commercial fractions. With the help of external belt conveyors, each fraction of crushed stone is stored separately. Gravel of fractions larger than $40 \mathrm{~mm}$ is loaded into the hopper of the feeder, the feeder provides a uniform supply of rock mass to the crusher, which crushes the gravel to a particle size of 5-20 mm [3].

The main disadvantage of the above mentioned complex of crushing and screening equipment is the feeding of the feedstock by the feeder of the loading hopper including lumps not exceeding the average size to the screens and then to the crusher, which is economically inexpedient. The design of the receiving hopper is proposed which allows combining the functions of loading the crusher and sorting material.

\section{Development of a receiving and segregation hopper with a construction novelty}

In the source raw material for the production of crushed stone, obtained from gravel and extracted with the help of hydraulic motors, the number of pieces exceeding $40 \mathrm{~mm}$ reaches $50 \%$ of the total volume. The separation of bulk materials into products of various sizes is one of the main processes in the production of crushed stone [4]. The reduction of the cost of the technological operation of the separation of the source material into standard classes and provision of stable production operation is ensured by the use of a vibrationsegregating device (Figure 1).

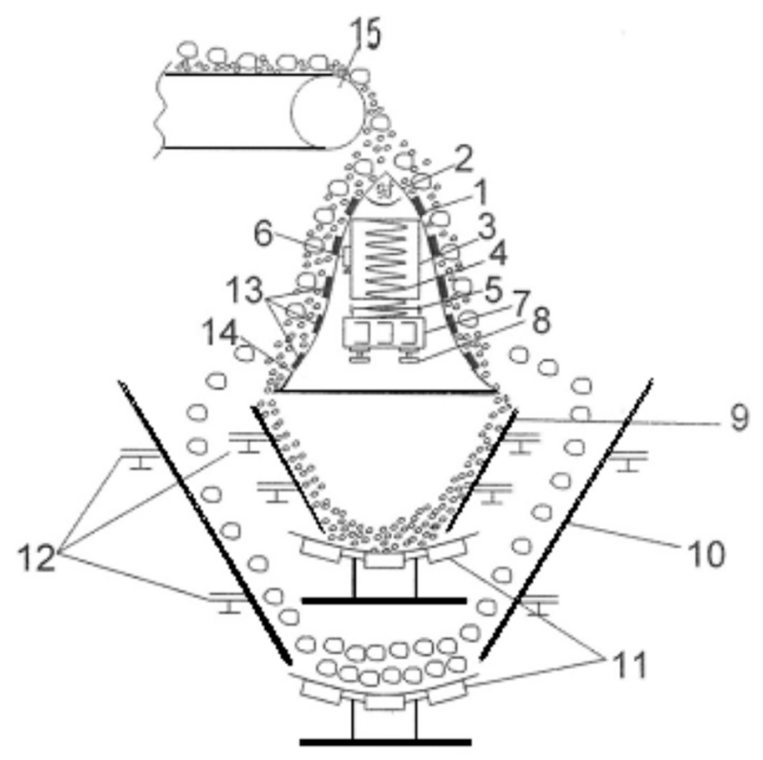

Figure 1. Vibration and segregation device for sorting of mineral construction raw materials by size:

1 - bell-shaped cone,

2 - lid,

3 - upper glass,

4 - springs,

5 - lower glass,

6 - vibrator,

7 - support frame,

8 - rails,

9 - upper hopper,

10 - lower hopper,

11- belt conveyor,

12 - support beams,

13 - rings,

14 - unloading part of the cone,

15 - loading conveyor

The technical result of the proposed development is to increase the efficiency of the receiving hopper as a device that segregates the feedstock at the initial technological stage of crushed stone production (Fig. 2) (RF patent 2016145713). 


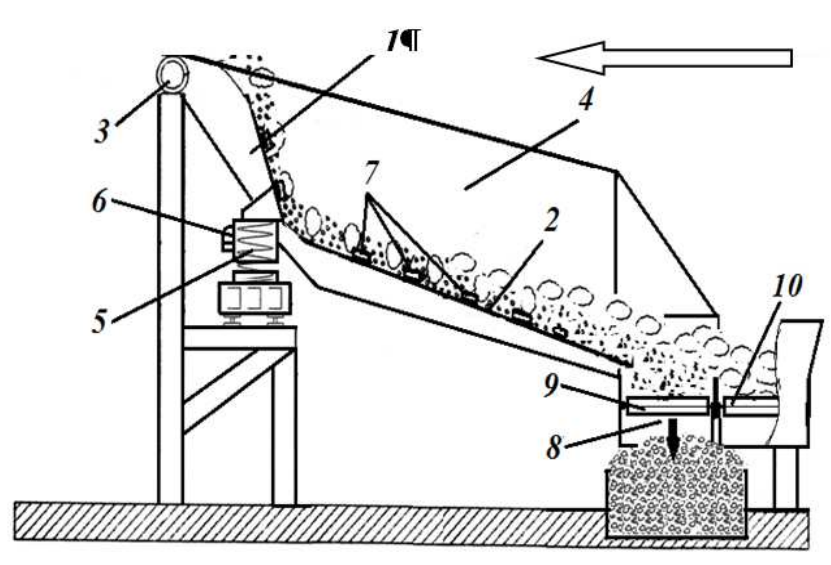

(a)

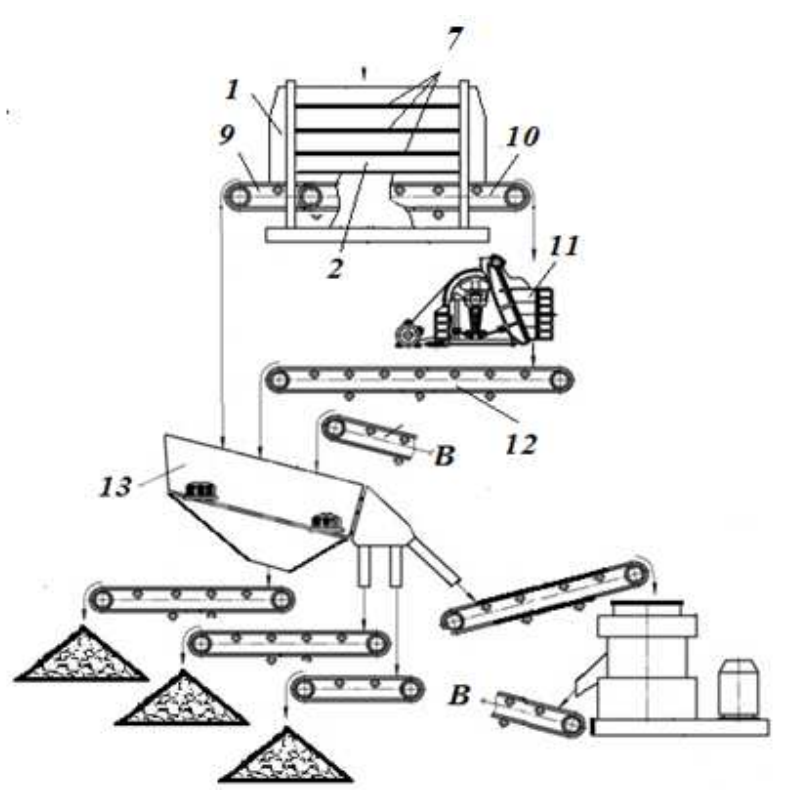

(b)

Figure 2. The complex of crushing and screening equipment: (a) - design of a receiving hopper with a descent segregation-vibration wall; (b) - circuit diagram of the apparatus of stone-crushing plant.

This device allows dividing the original rock mass into size classes by means of a separating surface equipped with a vibrator and a shock absorber.

The technical result is achieved due to the fact that in the proposed receiving-segregation hopper 1 a drain wall is made in the form of a curved surface of S-shaped and by means of a hinge 3 it is fixed on the side walls 4 . The downstream wall 2 rests on the shock absorber 5, equipped with a vibrator 6 . Along the entire height of the downstream wall 2, the transverse elements 7 are fixed at an equal distance from each other. The execution of the drain wall ensures the segregation of the feedstock at the initial technological stage.

The conveyor bottom 8 of the receiving hopper 1 is made in the form of two feeders 9-10, which structurally allows directing the separated small particles of the source material bypassing the crusher 11 of the primary crushing stage.

The principle of operation of the proposed receiving segregation hopper is as follows. The raw material is loaded into the receiving hopper 1 . The loading method is a floating crane unloading the barges. At the same time, the vibrator 6 is turned on, which creates vibrational movements. The vibrations are transmitted through the shock absorber 5 to the outlet wall 2, which vibrates with a vibration frequency of 1000 vibrations per minute and amplitude of 2-3 $\mathrm{mm}$.

The source material containing large and small particles rolls downward under the influence of gravitational force. In this case, due to vibration and friction forces, large particles float and small particles end up at the surface of the drain wall 2 with transverse elements 7 , the function of which is to reduce the speed of small particles rolling down.

As a result, small particles, approaching the lower edge of the drain wall 2 , have a movement speed that is much lower than the speed of large pieces. Due to the lower speed of movement, small particles fall on the conveying body of the feeder 9 and large particles, rolling in the upper layer at a much higher speed fall onto the conveying body of the feeder 10 .

Feeder 9 feeds fine material to conveyor 11, feeder 10 feeds coarse material to conveyor 12 . Feeder 10 feeds coarse material to crusher 11 , where material is crushed into pieces of medium size. Further, the material is fed by the conveyor 12 to the separation screen 13 . Feeder 9 feeds the fine material directly to the screen 13 . On the screen 13 the fine material is also fed by the feeder 9 bypassing the crusher 11 of the primary crushing stage.

Thus, the proposed receiving - segregation hopper with a descent segregation-vibration wall allows excluding the passage of the primary crushing stage up to $50 \%$ of the original rock mass due to the segregation of the feedstock at the initial technological stage. Therefore, it helps to reduce energy consumption for the production of a unit of the finished product and increase the productivity of the complexes of crushing and sorting equipment implementing the technology of crushed stone production [5].

\section{Research of operation process}

Bulk material moving along an inclined plane (bottom surface - a metal sheet of a sieve-free screen) under the action of gravity consists of particles, the shape of which, in the framework of modeling the operation process, is close to spherical.

We will consider the motion of a particle in the pure rolling mode, since only in this mode the particles of different sizes are separated according to the speed of their descent along an inclined plane, thereby providing the segregation of the material according to size classes.

As a result of the solution of the equations of motion of particles on a screen, it was found that the speed of 
rolling of a particle along a chute with a length $L$ with inclination angle $\alpha$ is

$$
V=\sqrt{2 g \operatorname{Lv}\left(\sin \alpha-f^{\prime} \cos \alpha\right)+V_{0}^{2}},
$$

Where $v=1-\mu$; where $\mu$ - particle shape factor for a sphere;

$\rho-$ particle radius of gyration, $\mathrm{m} ; \mu=\frac{\rho^{2}}{\rho^{2}+r^{2}}=\frac{2}{7} ;$ $f^{\prime}$ - rolling friction coefficient of a particle on a steel bottom; $\mathrm{V}_{0}$ - initial particle velocity, $\mathrm{m} / \mathrm{s} ; g-$ acceleration of gravity.

The rolling time of a particle can be determined by the following formula

$$
t=\frac{-2 V_{0}+\sqrt{4 V_{0}^{2}+8 q v l\left(\sin \alpha-f^{\prime} \cos \alpha\right)}}{2 q v\left(\sin \alpha-f^{\prime} \cos \alpha\right)}
$$

Based on the simulation results, we propose a condition under which the pure rolling mode is realized:

$f^{\prime}<\operatorname{tg} \alpha<\frac{f-f^{\prime} v}{\mu}$, where $f$ - coefficient of sliding friction of a particle along a steel chute

If the condition is not met, then the movement of particles combines sliding and rolling and the process of the separation of the material into fractions is disrupted. According to the given dependences, the speed of particles of a certain size at the exit of the screen is evaluated by the efficiency of material segregation into fractions.
Based on the described principles, modeling and assessment of the capacity of the hopper with a descent segregation-vibration wall $V_{l}$ is carried out according to the methodology proposed for sieve-free screening devices. The following parameters are taken into account: B - width of the drainage segregation-vibration wall $(\mathrm{mm}) ; 1$ - length of the drainage wall $(\mathrm{mm}) ; n_{1}$ - the height of steel teeth on a metal sheet; $h_{l}$ - the average height of the source material.

The capacity of the hopper is determined by the following formula:

$$
V_{1}=\left(L \cdot\left(\frac{n_{1}}{h_{1}}\right)^{1 / 3}\right) \cdot g \cdot t \cdot \sin \alpha,
$$

Where $t$ - the time of the fraction rolling down from the sheet

The results of the studies on the dependence of the capacity of the hopper $\left(V_{l}\right)$ on the size of the source material are shown in Figure 3. As a result of the analysis, the following characteristic was revealed:

$$
V_{1}=3,5 \cdot h_{1}^{-0,33} \text {. }
$$

The convergence of the data is confirmed by the coefficients of determination, equal to $\mathrm{R}^{2}=0,87$.

The error of the obtained formula is determined $\mathrm{m}_{\mathrm{v}_{1}}= \pm 0,06$.

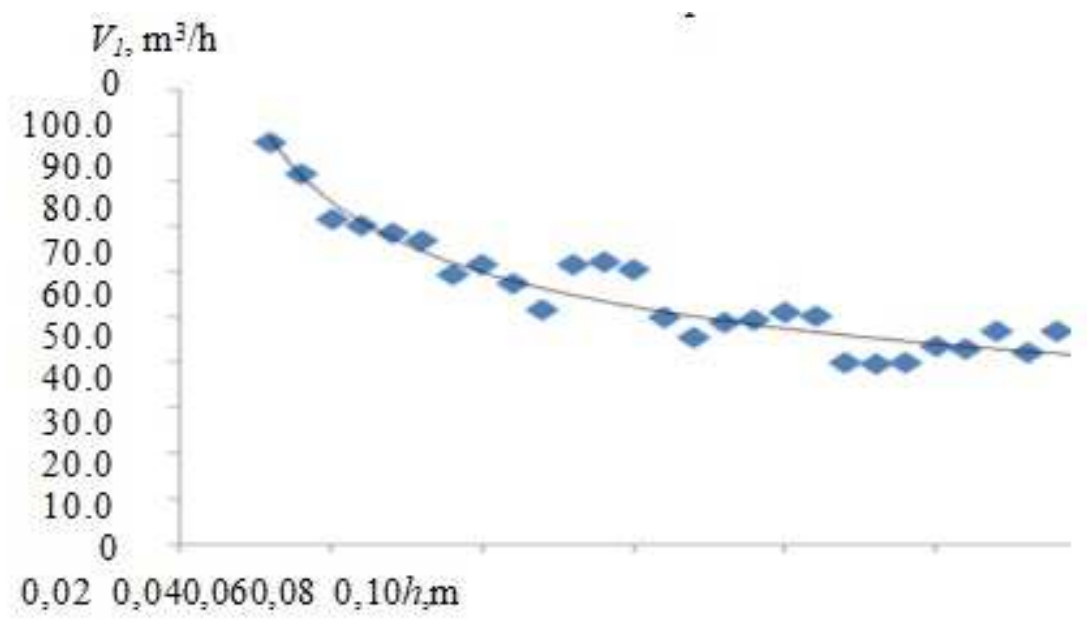

Figure 3. Graph of the dependence of the capacity of the hopper with a descent segregation-vibration wall $V_{l}$ on the size of the source material

As a result of calculations, it was found that:

- the optimal slope of the drain wall of the conical cover is $50^{\circ}$ angle;

- the outer surface of the drain wall in the loading has $70^{\circ}$ angle and at the bottom in the unloading has 30 $\circ$ angle;

It is necessary to note that the proposed improvement of crushing and screening equipment can also be used for beneficiation complexes in the development and transportation of coal, where a sorting cascade is used for sorting and crushing, with re-feeding to screens and crushers in order to prevent oversized loading The use of segregation-vibration equipment will eliminate the use of a return conveyor and re-passage of the sorting cascade.

\section{Conclusion}

1. The proposed receiving hopper with a descent segregation-vibration wall of the crushing and screening equipment complex with a constructive novelty provides the separation of the source material into two size classes.

2. It was found that it is necessary to conduct research in order to solve the following tasks:

- $\quad$ to perform analytical modeling of the trajectory of movement of sandstone particles along the inclined plane of the descent segregation-vibration wall;

- to conduct experimental studies of the motion of 
particles of a segregated material along an inclined plane and assess the convergence of experimental and calculated data;

- to clarify the methodology for the calculation of the trajectory of the particles of the segregated material along the inclined plane, taking into account the vibration of the drain wall and the actual shape of the sandstone particles, namely the spatial motion of the absolutely solid surfaces of particles located with some gaps;

- $\quad$ to carry out experimental studies and assess the convergence of experimental and calculated data.

\section{References}

1. Uttam Bol Shrestha Journal of Nepal Geological Society 58, 83-88, (2017)

2. A. Navarra, A. Menzies, A. Jordens, Waters K. International Journal of Mineral Processing 164, 45-55 (2017)

3. S. Miloslavskaya, A. Panychev, A. Myskina, P. Kurenkov IOP Conference Series: Materials Science and Engineering 698, 066059, (2019)

4. B. M. Bazrov, T. M. Gainutdinov Russian Engineering Research 40(4), 303-307, (2020)

5. Y. M. Lyashenko, D. N. Shurygin, E. A. Revyakina Procedia Engineering. International Conference on Industrial Engineering, ICIE 2017 1388-1394 (2017) 